\title{
Estratégias para Melhorar a Qualidade dos Textos de Alunos de Biologia do Ensino a Distância, em Consonância com os Objetivos de Desenvolvimento Sustentável \\ Strategies to Improve the Quality of Texts of Biology Students from Distance Learning, in Consonance with the Sustainable Development Goals
}

\author{
Jorge Luiz Ferreira Ramineli* \\ Magnólia Fernandes Florêncio de \\ Araújo' \\ 1 Universidade Federal do Rio Grande \\ do Norte. Avenida Senador Salgado \\ Filho, S/N - Lagoa Nova, Natal/RN, \\ Brasil. \\ *jorge.ramineli.126@ufrn.br
}

\section{Resumo}

O objetivo deste estudo foi apresentar e analisar a eficácia das estratégias interventivas propostas por um professor do curso de Licenciatura em Ciências Biológicas na modalidade a Distância da Universidade Federal do Rio Grande do Norte, as quais tinham a intenção de melhorar a qualidade do registro dos relatos escritos pelos alunos do estágio supervisionado, na perspectiva de se atingirem as metas propostas pelos Objetivos de Desenvolvimento Sustentável 4 e 10, Educação de Qualidade e Redução das Desigualdades, respectivamente. Para isso, foram analisadas três estratégias implantadas a partir do semestre 2017.1: a primeira delas, que aconteceu presencialmente, nos polos, correspondia à exposição dos problemas para os alunos e tutores; a segunda, também executada nos polos, foi a realização de uma atividade sobre o gênero textual roteirização; e a terceira estratégia aconteceu no formato de orientações das atividades na página da disciplina no ambiente virtual do Moodle Mandacaru. Após as intervenções foi possível evidenciar melhorias na qualidade dos textos postados pelos e-alunos, com maior criticidade do discurso, nas suas narrativas das ações pedagógicas. Percebeu-se também, no que se refere ao repensar a prática dentro do processo de formação docente, que os professores orientadores formadores se sentiram inseridos nesse papel, tanto no espaço virtual, quanto no tempo necessário para isso, estando conscientes da sua complementaridade na formação profissional do eu pedagógico desses futuros educadores e educadoras. Observou-se, ainda, que essas ações estavam em consonância com os objetivos 4 e 10, na medida em que se vincularam às suas premissas, a diminuição das desigualdades e a busca pela sustentabilidade.

Palavras-chave: Estágio supervisionado. Diário reflexivo. Intervenção crítica. Objetivos de desenvolvimento sustentável.

\section{(c) (i)}

Recebido 20/07/2020 Aceito 22/03/2021

Publicado 24/03/2021

\section{COMO CITAR ESTE ARTIGO}

ABNT: RAMINELI, J. L. F.; ARAUJO, M. F. F. Estratégias para Melhorar a Qualidade dos

Textos de Alunos de Biologia do Ensino a Distância, em Consonância com os Objetivos de Desenvolvimento Sustentável. EaD em Foco, v. 11, n. 1, e1129, 2021.

doi: https://doi.org/10.18264/eadf.v11i1.1129 


\section{Strategies to Improve the Quality of Texts of Biology Students from Distance Learning, in Consonance with the Sustainable Development Goals}

\section{Abstract}

The objective of this study was to present and analyze the effectiveness of the intervention strategies proposed by a professor of the Biological Sciences Degree course in the Distance modality of Federal University of Rio Grande do Norte, which were intended to improve the quality of the record of the reports written by the students of the supervised internship, with a view to achieving the goals proposed by Sustainable Development Goals 4 and 10, Quality Education and Reduction of Inequalities, respectively. For this, three strategies implemented from the 2017.1 semester were analyzed: the first one, which took place in person, at the hubs, corresponded to the exposure of problems to students and tutors; the second, also performed at the poles, was the realization of an activity on the textual genre scripting; and the third strategy took place in the format of activity guidelines on the discipline page in the virtual environment of Moodle Mandacaru. After the interventions it was possible to evidence improvements in the quality of the texts posted by the e-students, with greater criticality of the discourse, in their narratives of the pedagogical actions. It was also noticed, with regard to rethinking the practice within the process of teacher training, that the guiding teacher trainers felt inserted in this role, both in the virtual space and in the time necessary for that, being aware of their complementarity in training of the pedagogical self of these future educators. It was also observed that these actions were in line with objectives 4 and 10, insofar as they were linked to its premises, the reduction of inequalities and the search for sustainability.

Keywords: Supervised internship. Reflective diary. Critical intervention. Sustainable development goals.

\section{Introduzindo a Investigação}

Os cursos de graduação nas instituições públicas de Ensino Superior (IES) no Brasil, tanto o Bacharelado, quanto a Licenciatura, podem ser oferecidos na integra ou parcialmente, em duas modalidades ${ }^{1}$, presencial e a distância, e para manter a qualidade desse ensino, essas instituições dependem de orçamentos e planos financeiros governamentais sérios que possam garantir essa manutenção, que no caso das Universidades Federais é atribuição da Subsecretaria de Planejamento e Orçamento ${ }^{2}$.

Na Universidade Federal do Rio Grande do Norte (UFRN), que passou por um processo de reestruturação e que a levou a um real crescimento e desenvolvimento promovido pelas propostas vindas via Reuni (Programa de Apoio e Planos de reestruturação e Expansão das Universidades Federais), essa necessidade orçamentária não foi diferente. Com esse crescimento visível, a instituição vinha conseguindo atender a grandes contingentes de alunos, além de poder promover, cada vez mais, a interiorização do

1 De acordo com o MEC/CNE-CP, resolução número 2 de 01 de julho de 2015, para o ensino superior no Brasil.

2 Tem por atribuição principal planejar, coordenar e supervisionar a execução das atividades relacionadas com os Sistemas de Planejamento e de Orçamento Federal, de Administração Financeira Federal e de Contabilidade Federal, no âmbito do MEC (MEC/SPO, 2018). 
ensino superior com a consolidação do Ensino a Distância (EaD), que ganhou espaço nos últimos 10 anos. Entretanto, mesmo com essa expansão, não podemos esquecer que o grande desafio das IES é garantir, prioritariamente, a qualidade do ensino ofertado durante a formação desses novos profissionais.

Diante desses desafios, cabe em boa parte à esfera educacional promover a formação consciente à Educação para o Desenvolvimento Sustentável (EDS), e é importante que esse comprometimento esteja direcionado para o ato de ensinar e aprender, ou seja, na prática pedagógica entre a atitude e a reflexão, logo, uma práxis pedagógica dialógica e crítica. Nesse sentido, evocamos as ideias de Paulo Freire (1995), que aprofunda o conceito de práxis, no universo pedagógico, como sendo a capacidade do sujeito de atuar e refletir, isto é, de transformar a realidade de acordo com as finalidades delineadas pelo próprio ser humano, por isso, uma práxis pedagógica transformadora que liberta.

Portanto, ao trazermos em cena os cursos superiores de formação docente, em ambiente de Ensino a Distância, enxergamos a disciplina de estágio supervisionado, uma das mais importantes, pois consideramos que esse momento é uma oportunidade impar que esse aluno terá ao vivenciar, na prática, o dia a dia de uma rotina escolar. Assim, nessa busca da constituição da figura do eu pedagógico, desse professor em formação, é de extrema importância que o eu formador, na figura do professor da disciplina de estágio, promova ações reconstrutivas do discurso e das ações pedagógicas desse e-aluno, que por vezes, ainda insiste em aparecer de maneira descontextualizada, com ausência de coerência e coesão das ideias.

Sendo assim, repensar as estratégias de ensino que contemple um planejamento voltado para o ato de aprender é, certamente, o fio norteador que esse professor formador terá que desenovelar na busca da melhoria desse discurso narrativo, em que muitas vezes aparece sem muita significação nas atividades apresentadas por grande parte dos alunos em uma disciplina de estágio. Logo, diante dessa necessidade latente em buscar a melhoria da qualidade do ensino pelo viés das atividades realizadas durante a disciplina de estágio, em particular, do curso de Licenciatura em Ciências Biológicas, pergunta-se: ações interventivas realizadas pelos professores formadores terão papel importante no resgate da qualidade dos textos produzidos pelos alunos da EaD, futuros docentes?

Além disso, cuidar dessas ações pontuais que refletem diretamente na melhoria da formação desse futuro profissional da educação, consequentemente nos remete a pensar os desafios que a universidade pública tem pela frente, ao levantar a necessidade pujante de também ter que manter a qualidade desse ensino, agora pensado remotamente, na realidade da EaD.

É nessa perspectiva, de melhorar a qualidade do ensino de maneira igualitária para todos, que a UFRN aderiu a proposta dos Objetivos de Desenvolvimento Sustentável ${ }^{3}$ (ODS), lançados pela ONU em 2015, que fazem parte das metas lançadas pela agenda 2030 para o Desenvolvimento Sustentável, na tentativa de levar temáticas em torno da Educação para a Sustentabilidade ${ }^{4}$ na sua forma mais ampla (figura 1).

3 Na Cúpula das Nações Unidas sobre o Desenvolvimento Sustentável ocorrido de 25 a 27 de setembro de 2015, os líderes de governos e de estado de 193 países adotaram a Agenda 2030 para o Desenvolvimento Sustentável, a qual contém um conjunto de 17 Objetivos de Desenvolvimento Sustentável (ODS) e 169 metas. (ONU, 2016, p. 7).

4 Como a liberdade, a justiça e a democracia, a sustentabilidade não tem um significado único e comum. A sustentabilidade apresenta diferentes significados em diferentes ideologias políticas e programas sustentados por diferentes tipos de conhecimentos, valores e filosofias. Como seu significado é contestado, uma função fundamental da Educação para a Sustentabilidade (ES) é ajudar as pessoas a refletir e agir sobre esses significados de maneira mais informada e democrática. (HUCKLE, 2014, p. 23) 
Figura 1: ODS propostos pela ONU na agenda 2030 para o desenvolvimento sustentável. Observar os objetivos 4 - educação de qualidade e 10 - redução das desigualdades.

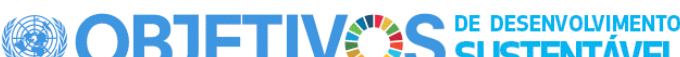
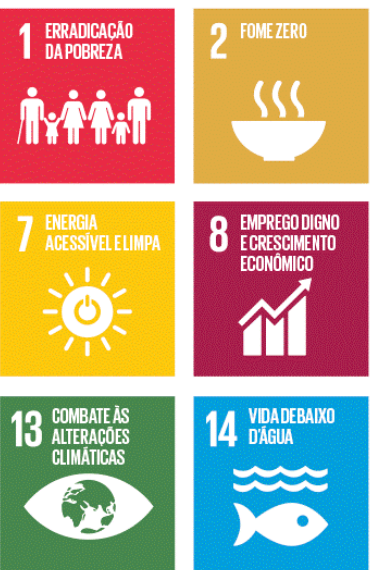
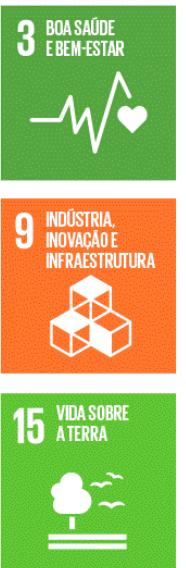
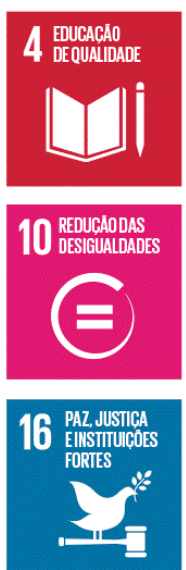
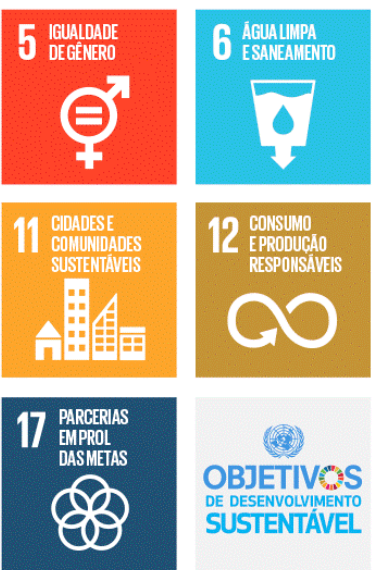

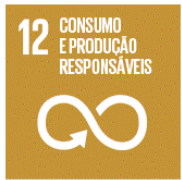

(9)

OBJETIVOS DE DESENVOLVIMENTO

Fonte: Disponível em: https://nacoesunidas.org/pos2015/agenda2030/ - acesso em:15 mar. de 2021.

Portanto, refletindo a respeito da manutenção dessa qualidade do ensino na modalidade a distância, alguns questionamentos vieram à tona quando passamos a analisar com mais profundidade as narrativas produzidas pelos estagiários, em que nos revelou um problema de base do entendimento do discurso, ou seja, textos pobres em coerência e coesão.

Diante disso, é objetivo desse artigo apresentar algumas estratégias interventivas propostas pelo professor orientador formador, ao registro dos relatos escritos pelos alunos do estágio supervisionado do curso de Licenciatura em Ciências Biológicas na modalidade a Distância da Sedis/UFRN, além de poder apresentar as contribuições dessas estratégias para a melhoria na qualidade da escrita dos Diários Reflexivos, na perspectiva de manutenção da oferta justa de um ensino público de qualidade, estando de acordo com os ODS 4 e 10, Educação de Qualidade e Diminuição das Desigualdades, respectivamente.

\section{Embasamento Teórico}

Para o Ministério da Educação a Educação a Distância no Brasil é considerada modalidade educacional, cujas mediações de ensino e aprendizagem se dão por meio das ferramentas de tecnologias de informação e comunicação (BRASIL, 2017). Por outro lado, a EaD também tem sido considerada como ação de política pública com propósito de promover a ampliação, a democratizar, além de estimular a interiorização do ensino superior público (ARRUDA, 2015).

Portanto, apoiar esses propósitos para que os cursos de EaD assumam e atuem como políticas públicas, não sendo tratados apenas como mais uma modalidade educacional é, por sua vez, movimentar-se em direção à consolidação de comunidades que anseiam por mais justiça e igualdade social. Logo, esse movimento se faz essencial, pois incentiva os cursos de Educação a Distância a atuar como instrumento disseminador da sustentabilidade na sua forma mais ampla, além de fortalecer a democratização do ensino superior, ao atingir as regiões mais distantes dos grandes centros urbanos. 


\subsection{O Ambiente Moodle Mandacaru}

Criada em 2003, a Secretaria de Educação a Distância (Sedis) da Universidade Federal do Rio Grande do Norte (UFRN) oferta, atualmente, 9 cursos de graduação distribuídos por 14 polos no estado do Rio Grande do Norte. Esta secretaria tem como objetivo principal, a promoção do ensino na modalidade a distância, ao mesmo tempo em que instiga a utilização das tecnologias de informação e comunicação como ferramenta de ensino e aprendizagem (PORTAL SEDIS, 2019.a). Além disso, a Sedis apresenta a EaD como instrumento que oportuniza a UFRN à ampliação do número de cursos e vagas ofertadas, fato ligado diretamente ao ODS 10, pois tem a ver com os esforços para a diminuição das desigualdades sociais.

Com a abertura da secretaria de EaD da UFRN, houve então, a necessidade da existência de um ambiente virtual que acolhesse as necessidades de alunos, cada vez mais interioranos, em consonância com os princípios básicos do ensino a distância. Para isso a Sedis passou a utilizar o Modular Object-Oriented Dynamic Learning Environment - Moodle, um software livre que funciona em qualquer ambiente virtual, voltado para programadores e acadêmicos da educação, como ferramenta "podendo ser aplicado tanto d̀ forma como foi feito, como a uma sugestiva maneira pela qual um estudante ou um professor poderia integrar-se estudando ou ensinando em um curso on-line" (PORTAL SEDIS, 2019.b). Em 2014, a Sedis desenvolveu um formato exclusivo denominado Mandacaru, apresentando inovação e modernidade ao seu ambiente que se integra tanto aos cursos de graduação, quanto aos de pós-graduação a distância (PORTAL SEDIS, 2014).

É nessa capacidade de promover a integração dos diferentes aprendizados, possibilitada pelo Moodle Mandacaru, que a proposta da Educação para a Sustentabilidade poderá encontrar caminhos para se chegar aos terrenos mais remotos dos grandes centros, visando colocar em prática um dos compromissos mais importante da Agenda 2030 para o Desenvolvimento Sustentável, em que ninguém “seja deixado para trás" (ONU, 2016. p. 1).

\subsection{O Estágio e a Formação de Professores na EaD/Sedis}

Temos considerado e, não é de hoje, que a estrutura curricular dos cursos de formação docente é, sem dúvida, um dos grandes desafios para as instituições de ensino superior e, nessa busca por uma melhor compreensão desse problema, ventilamos que esses cursos ainda carregam o peso de uma histórica tendência à descontextualização e segmentação curricular, em que "o conhecimento é fragmentado em disciplinas isoladas, distintas e distantes das experiências, dissociadas da vida." (MORAES, 2000, p. 99).

Nessa direção, ao pensarmos nas possíveis reestruturações desse currículo, também teremos como um desafio que ainda persiste na atualidade, principalmente nos cursos de formação de professores, buscar uma maior valorização das disciplinas que prevaleçam uma linha formativa voltada para a efetiva consolidação à prática docente no ambiente escolar, tendo em vista a presença de propostas curriculares fragilizadas, como a apresentada por Gatti (2010, p. 1373), em que, ao realizar um levantamento das características e problemas da formação de professores no Brasil, tem-se, por exemplo, que nas "licenciaturas em Ciências Biológicas a carga horária dedicada à formação específica na área é de 65,3\% e, para formação para docência, registra-se percentual em torno de apenas 10\%".

Inserindo outro dado, também preocupante, à problemática da carga horária sinalizada anteriormente, é importante relatar que outros esforços deverão ser considerados na tentativa de resgatar o número de alunos matriculados que diminuiu gradativamente nos cursos de EaD da UFRN entre os anos de 2014 a 2018, como mostrado na tabela 1. Essa diminuição parece ter sido um fenômeno regional, tendo em vista que os dados do censo apresentado pela Associação Brasileira de Educação a Distância em 2018 mostram o contrário, ou seja, um aumento significativo no número de matrículas em cursos regulamentados totalmente a distância no mesmo período (ABED, 2019). 
Tabela 1: YYYY em números de alunos entre 2014 e 2018.

\begin{tabular}{|l|c|c|c|c|c|}
\hline $\begin{array}{c}\text { No de Alunos } \\
\text { Matriculados/ } \\
\text { Graduação }\end{array}$ & 2014 & 2015 & 2016 & 2017 & 2018 \\
\hline Graduação presencial & 26.784 & 27.865 & 26.488 & 27.789 & 24.680 \\
\hline Graduação a distância & 3.954 & 2.934 & 1.928 & 2.239 & 1.248 \\
\hline Total & 30.738 & 30.799 & 28.416 & 30.028 & 25.928 \\
\hline
\end{tabular}

Fonte: PROPLAN/ SIGAA/ SIGRH/ Relatório PROGESP 2018. Disponível em: https://ufrn.br/resources/documentos/ ufrnemnumeros/UFRN-em-Numeros-2014-2018.pdf. Acesso em: 13 jan. 2021. Dados coletados no SIGAA (Sistema Integrado de Gestão de Atividades Acadêmicas). Adaptado pelo autor.

Entender melhor essa diminuição no número de alunos matriculados em cursos da EaD da Universidade Federal do Rio Grande do Norte é importante, porém investigações nessa direção não serão alvo deste artigo. Todavia, uma possível causa desse fenômeno pode estar vinculada ao desligamento da Sedis da Universidade Aberta do Brasil (UFRN/PROPLAN, 2020), fato que trouxe um agravamento da situação, já que entre o período de 2018 a 2020 não houve nenhum exame de seleção para ocupar possíveis novas vagas em quase todos os cursos da EaD da UFRN.

Outro fato que pode estar ligado a essa diminuição do número de alunos matriculados é a proposta do governo federal de diminuir os investimentos nessa modalidade no que diz respeito aos cursos de formação docente, tendo em vista que, atualmente, a intenção do Ministério da Educação para a educação profissional e tecnológica a distância é focar seus esforços, pelo menos no Rio Grande do Norte, em cursos na área da "saúde, na produção de equipamentos de proteção e outros produtos necessários para os tratamentos, bem como por profissionais dedicados aos cuidados de idosos" (MEC, 2020).

Retomando o pensamento para a importância da valorização da qualidade das disciplinas formativas voltadas para a consolidação das práticas docentes nos cursos de formação de professores, é essencial trazermos em cena a disciplina de estágio supervisionado e a sua efetiva realização nas escolas.

Para isso, é fundamental que os educadores desse ambiente virtual da EaD, os e-professores, sejam o mais claros possível nas suas orientações, evitando os prováveis ruídos que possam vir a surgir nesse momento. Portanto, ao iniciá-las, é importante que esse e-professor orientador leve às claras todas as regras e direcionamentos necessários para que o seu e-aluno realize bem o seu estágio, agora em um ambiente virtual.

Nesse caminho, também será essencial que o e-professor orientador, além de buscar melhorias na qualidade das suas orientações para os e-alunos da disciplina de estágio no mundo remoto da EaD, deve, acima de tudo, estar disponível para isso, ou seja, tomar a prática do feedback como rotina de um trabalho que faz parte de um processo denominado comunicação virtual ${ }^{5}$, pois:

[...] a postura do educador deve ser de mediação e parceria com o estudante durante o aprendizado para se obter resultados satisfatórios e, como ferramenta relevante de avaliação o feedback é fundamental como resposta aos estímulos podendo ser formativo, onde o aprendiz recebe o feedback com a intenção de modificar o seu comportamento ou ponto de vista buscando o seu aperfeiçoamento; como feedback formativo pode ser "diretivo"(que aponta o que precisa ser corrigido ou modificado) e "sugestivo"(que apresenta comentários e sugestões como orientação ao revisar o trabalho.(DOSE, 2017, p. 1570).

5 Toda a comunicação que se faz usando um computador. Podemos comunicar recorrendo ao teclado, ao som e à imagem. A comunicação pode ocorrer em tempo real - síncrona (bate-papo), ou off-line - assíncrona, deixando mensagens (e-mails). (FRANCO, 2007, p. 1). 
Considerando que, independentemente da modalidade, se de um curso presencial ou a distância, os estágios supervisionados serão sempre considerados como momentos transformadores, pois é estagiando que o futuro professor vivenciará experiências impares na sua formação, já que, só aquele que embarca em uma sala de aula poderá sentir o que é ser um professor na sua verdadeira essência. Dessa forma, o estágio não pode ser considerado como mais um momento de se realizar atividades individualizadas, pelo contrário, o estágio supervisionado deve priorizar um conjunto de ações colaborativas e cooperativas entre todos os envolvidos. Na Sedis, esse estagiário tem atuado na coletividade com os colegas de sala, tutores de estágio presenciais e a distância, professores colaboradores e o professor orientador da disciplina (BARBOSA \& NORONHA, 2013, p. 18), não se esquecendo de mencionar que todo esse ambiente colaborativo é efetivamente consolidado via interface virtual apresentada pela plataforma Moodle/Mandacaru.

Assim, além de promover o exercício às ações cooperativas e colaborativas com os sujeitos envolvidos direta e indiretamente na sua formação, o período do estágio supervisionado será também um momento em que o e-aluno deverá refletir sobre si mesmo, seu eu em formação, lançando uma série de perguntas que o leve a pensar sobre a sua práxis pedagógica que, segundo as ideias de Freire, deságuam em uma educação verdadeiramente transformadora, em que "a práxis, porém, é reflexão e ação dos homens sobre o mundo para transformá-lo. Sem ela, é impossível a superação da contradição opressor/oprimido" (FREIRE, 1987, p. 38).

Por outro lado, quão importante quanto resgatar essas experiências no estágio em um curso de formação de professores na $\mathrm{EaD}$, também será primordial que os e-alunos se familiarizem o quanto antes com os ambientes virtuais oferecidos na EaD, condição essencial para a sua permanência em um curso como esse, já que a utilização dessa ferramenta de aprendizagem remota, na formação profissional em geral, vem sendo ampliada diariamente, tornando-se uma prática cada vez mais comum e evolutivamente sem volta.

Por isso é tão importante compreender as principais razões que levem esses e-alunos a desistirem dos seus cursos, pois esse entendimento poderá ajudar em ações futuras voltadas ao combate da evasão. Nessa perspectiva, Luz e colaboradores traçaram uma caracterização dos principais motivos que levam professores a abandonar eventuais cursos online.

[...] as taxas de evasão nesses cursos são altas e provavelmente não relacionadas às características dos cursos. A falta de tempo devido a uma carga de trabalho pesada, bem como problemas tecnológicos associados à qualidade da conexão de internet a que os professores têm acesso foi responsável pela maioria das razões para a desistência. (LUZ et al., 2018)

Há mais de uma década, Messa (2010), que já estudava a utilização de Ambientes Virtuais para as Aprendizagens Significativas - AVAS nos ajuda a fortalecer essa ideia de que há uma concordância com essa evolução da EaD como realidade educacional, já que o MEC vinha na tentativa de produzir materiais didáticos que pudessem servir como referenciais para as mais variadas ofertas de cursos na modalidade em educação a distância. Por outro lado, quando trazemos os verdadeiros motivos que têm provocado evasões nos cursos de EaD pelo Brasil, temos cada vez mais a certeza de que não basta apenas ofertar vagas nessa modalidade, mas, também, agir seriamente na promoção da qualidade desses cursos, além de repensar estratégias que possam garantir a permanência desses e-alunos no ensino virtual.

Nessa perspectiva, poder refletir e agir sobre a necessária e justa participação de todos no Moodle/ Mandacaru, visando as melhorias na educação, com a possibilidade do estreitamento da faixa que marca as desigualdades sociais, nos dá um fôlego de esperança ao presenciarmos alunos e alunas residentes em regiões bastante remotas, ainda se valendo dos cursos de EaD para realizarem uma graduação. Fatos como estes nos levam a declarar, com segurança, que pelo menos os ODS 4 e 10 estão na lista de metas a serem alcançados pela Universidade Federal do Rio Grande do Norte, na busca pela sustentabilidade na sua concepção mais ampla. 


\subsection{As Narrativas, o Diário Reflexivo e as Intervenções}

O trabalho com as narrativas inseridas nos cursos de formação de professores na modalidade a distância é, acima de tudo, um desafio, pensando nesse instrumento como uma grande oportunidade de praticar a escrita e reescrita, essencial para resgatar as vivências do sujeito em formação, dando a ele a possibilidade de exercitar a produção de autoavaliações, ressignificando, assim, suas ações diante da prática do fazer pedagógico durante as atividades do estágio supervisionado. Reforçando a ideia da importância de se ter presente uma formação reflexiva nos cursos de licenciatura, Machado e Carvalho, ao analisarem as experiências formadoras da docência, verificaram que:

Oportunizar reflexões que estabeleçam relações com fatos e vivências do cotidiano que extrapolem a formação acadêmica é um imperativo na proposição de cursos de formação de professores. (MACHADO \& CARVALHO, 2013, p. 12).

Nessa perspectiva, o Diário Reflexivo torna-se ferramenta virtual essencial na busca dessa ressignificação por meio das narrativas, pois aqui o professor em formação terá a chance de refletir de maneira crítica, a sua prática pedagógica, seus anseios e angustias e suas ações perante as problemáticas diárias de uma sala de aula, prezando pela qualidade da educação, nesse caso em particular, a EaD da UFRN.

Diante da ideia da experiência, vivenciada nas práticas pedagógicas adquiridas durante o estágio supervisionado, como propósito consolidador do eu em formação, Machado e Carvalho (2013, p. 2) explicam que essa relação, experiência/formação "está embasada na perspectiva de compreensão de que os processos de formação do sujeito estão em consolidação ao longo de sua trajetória de vida." Por esse ponto o de vista, as narrativas biográficas têm o podem de levar o professor em formação à consolidação de uma análise das experiências vividas.

[...] é uma aprendizagem que articula, hierarquicamente: saber-fazer e conhecimentos, funcionalidade e significação, técnicas e valores num espaço-tempo que oferece a cada um a oportunidade de uma presença para si e para a situação, por meio da mobilização de uma pluralidade de registros. (JOSSO, 2004, p.39)

Todavia, para que o aluno da EaD consiga analisar e avaliar criticamente a sua prática e que essa avaliação seja realizada em tempo hábil para que se possa retomar aquilo que poderá ser melhorado, ainda durante o percurso da disciplina, é essencial que o professor orientador formador consiga atuar positivamente nessa intervenção. Está na figura desse professor orientador formador, que o e-aluno de estágio da EaD costuma depositar a sua confiança e a certeza de uma boa formação.

É, portanto, diante dessa figura do e-aluno, o eu pedagógico em formação, que o e-professor orientador da disciplina de estágio deverá promover suas ações interventivas, reconstrutivas do discurso, que por vezes, chega com ideias desalinhadas. É nesse outro, figura do e-professor orientador, que esse e-aluno busca "uma visão que o complete, o faz ver o mundo e a si mesmo, por isso a necessidade do olhar outro que me chega como complementação". (CASADO ALVES, 2015. p. 2).

Resta então, a esse e-professor, nutrir a formalização do discurso e das ações desse e-aluno, lançando mão de atividades que promovam o resgate da prática pedagógica desse sujeito e, sem dúvida, uma das estratégias bem vista para esse fim é a escrita e reescrita de memórias narradas das experiências vividas durante as atividades dos estágios. 


\section{Apresentação Metodológica da Investigação}

Apoiado no perfil geral da problematização apresentada anteriormente, justifica-se a utilização de uma metodologia de pesquisa com caráter de um estudo teórico e empírico. Teórico, pois se levantou uma sólida bibliografia que embasará e complementará os resultados que se sucederam após as coletas dos dados. É também uma pesquisa empírica por evidenciar vivências dos atores envolvidos, pois “investiga um fenômeno contemporâneo em profundidade e em seu contexto de vida real" (YIN, 2010, p.39), experiências estas que emergirão conforme as análises críticas das atividades apresentadas remotamente.

Adicionalmente a esses procedimentos de pesquisa que se conectam nesse artigo, outra questão metodológica deve ser verificada e diz respeito ao tipo de abordagem que será utilizada que, nesse caso, trata-se de uma análise qualitativa de estudo de caso, tipo de investigação empírica "caracterizada pelo estudo profundo e exaustivo de um ou de poucos objetos" (GIL, 2008, p. 57), em que serão realizadas análises de textos produzidos por alunos para uma atividade chamada Diário Reflexivo - tarefa que veremos mais adiante.

Essas análises ocorreram em textos de 62 e-alunos do curso de Licenciatura em Ciências Biológicas, na modalidade a distância (EaD) da Secretaria de Educação a Distância (SEDIS), da Universidade Federal do Rio Grande do Norte (UFRN) distribuídos em 6 polos, Nova Cruz, Luís Gomes, Currais Novos, Caicó, Macau e Guamaré, todos municípios do estado do Rio Grande do Norte, Brasil. As intervenções ocorreram durante o período de março a novembro de 2017 e do total de alunos investigados, 23 estavam cursando a disciplina de Estágio Supervisionado I, 22 deles o Estágio Supervisionado II e 17 cursavam a disciplina de estágio III.

A respeito dos componentes curriculares do estágio, nas três disciplinas, citadas acima, os e-alunos deveriam realizar atividades em três ambientes. O primeiro deles de forma virtual, via Moodle/Mandacaru, ou quinzenalmente de forma presencial, ambos com a presença direta dos tutores de estágio. O segundo ambiente a ser visitado pelo estagiário foi a escola, escolhidas por eles, onde foram acompanhados pelo ProfessorColaborador, responsável pela disciplina de estágio na instituição. Essas disciplinas eram desenvolvidas pelos estagiários prioritariamente em instituições públicas de ensino básico, em turmas do Ensino Fundamental II e Médio, somando-se 400 horas, de um total de 2910horas (UFRN, 2020), ou seja, apenas $13.7 \%$ do curso, estão reservados às práticas na escola.

Por último, o aluno deveria cumprir algumas atividades propostas pelo Professor Orientador Formador, responsável pela disciplina de estágio, que nesse caso acontecia preferencialmente no ambiente virtual Moodle/Mandacaru. Dentre essas atividades, propostas pelo e-professor formador, algumas delas são específicas de cada estágio, mas outras são comuns e retomadas nas três disciplinas, como é o caso da atividade Diário Reflexivo, instrumento essencial no resgate às vivências dos sujeitos em formação.

A análise das experiências formadoras por meio da intervenção docente na elaboração das narrativas biográficas na atividade Diário Reflexivo foi o instrumento metodológico utilizado na pesquisa que deu origem a esse artigo, porém uma ação organizativa simples, na página das disciplinas de estágio, foi essencial. Com esse intuito, o primeiro passo foi criar um ambiente específico para a coordenação da disciplina, já que antes, assuntos burocráticos e pedagógicos eram postados no mesmo ambiente, causando muitos ruídos nas informações e orientações.

Quanto ao Diário reflexivo, essa é uma tarefa proposta para os alunos das disciplinas dos três estágios a distância da Sedis/UFRN. Os e-professores orientadores lançam mão desta atividade, por acreditar que ela tem a função de fazer com que esses alunos resgatassem suas experiências vividas durante os estágios na EaD. Seu intuito principal foi fazer com que esse e-aluno passasse a ter como produto o conhecimento de si, sendo capaz de se interrogar, aprender e transformar sua prática por meio das suas experiências concretizadas pelo registro (JOSSO, 2004). 
Analisando as narrativas produzidas pelos estagiários, tutores a distância e professores orientadores detectaram que estes registros estavam sendo postados, na página da disciplina, sem critérios éticos, fora dos padrões formais da língua e sem o compromisso de se assegurar o direto de autoria, já que muitas atividades continham evidências de plágios. Tínhamos então, um problema a ser resolvido e, para isso, a equipe de professores orientadores, em parceria com os tutores a distância, traçaram metas e elaboraram estratégias para alcançá-las, que nesse caso, a principal delas foi a melhoria da qualidade dos registros das narrativas postadas na atividade Diário Reflexivo. Tomando como ponto de partida a questão acima, visando à melhoria dos registros narrados por estes e-alunos, a equipe focou em três ações, chamadas aqui de estratégias interventivas:

1. Exposição dos problemas nos polos: realizou-se uma visita presencial em cada um dos seis polos da EaD do programa UAB/Sedis/UFRN, localizados nos municípios de Nova Cruz, Luís Gomes, Currais Novos, Caicó, Macau e Guamaré, todos no estado do Rio Grande do Norte, com a finalidade de levar aos alunos a problemática que viera à tona com as leituras e avaliações dos registros dos Diários Reflexivos. Esse momento durou cerca de 2 horas em cada polo visitado, e nele foram pontuados, aos estagiários e tutores, os principais problemas detectados, como a necessidade da formalização linguística dos registros; a inadequação da utilização do espaço virtual, como veículo de reclamações, a ponto de faltar com respeito e ética diante dos discursos queixosos; por último, a problemática que envolve a presença dos plágios em grande parte dos relatos produzidos. As palestras presenciais objetivavam conscientizar cada aluno fazendo com que ele pudesse se perceber como agente ativo nas observações negativas percebidas nos registros e, que havia espaço para melhoras. Esses momentos provocaram debates enriquecedores que ajudaram a construir, não apenas nos estagiários, mas também em todos os outros agentes envolvidos, uma postura mais crítica perante o que se escreve.

2. Atividade interventiva nos polos: nas mesmas viagens de visitas aos polos, em que foram expostos os problemas para os alunos, a equipe de professores orientadores e tutores a distância levaram a proposta de realizar uma atividade que os levassem a compreensão da importância de organizar suas ideias, antes mesmo de começar a escrever os relatos nos Diários Reflexivos. Escolheu-se então uma atividade de roteirização, em que no primeiro momento, realizou-se uma breve introdução sobre o assunto, com duração de cerca de $2 \mathrm{~h}$. Embora seja considerado um gênero textual, que tem a ver com a produção escrita ou oral de um texto, nem sempre o trabalho de roteirização é percebido como sendo um artifício literário. Comparato (2007, p.28), coloca que “O roteiro é o princípio de um processo visual e não o final de um processo literário". Esse pensamento levou então, à prevalência da técnica de roteirização para dentro das ações artísticas, em especial as artes visuais como é o caso do cinema, “...o roteiro cinematográfico é considerado o ponto de partida da narrativa audiovisual, ..." (CIRINO, 2012, p. 49). Meneses, ao trazer uma discussão a respeito da Cultura Visual, mostra que, já no início da década de 1990, dá-se:

[...] uma percepção cada vez mais ampliada, inclusive fora dos limites acadêmicos, da importância dominante da dimensão visual na contemporaneidade. A difusão da comunicação eletrônica e a popularização da imagem virtual obrigam à procura de novos parâmetros e instrumentos de análise, que articulam os esforços da Sociologia, Antropologia, Filosofia, Semiótica, Psicologia e Psicanálise, Comunicação, Cibernética, Ciências da Cognição. (MENESES, 2003. p. 23)

Reforçando essa ideia, estando os filmes constituídos por tramas cada vez mais intricadas, o planejamento textual tornou-se cada vez mais indispensável (MCGILLIAN apud SOUZA, 2016). Dessa forma, o trabalho de roteirização passa a ter uma ideia de planejamentos textual, essencial para o processo de uma boa escrita, que tem por objetivo evidenciar a contextualização e coesão das narrativas, justificando-se, por si só, a escolha desse gênero para servir de aporte para os alicerces de uma boa narrativa. 
Diante do exposto, após a explanação do tema, a equipe organizou os alunos em duplas e lançou a proposta para que fosse feita uma atividade de roteirização, cujos temas foram de livre escolha. As duplas montavam, por meio de atividade de recorte e colagem de imagens de revistas, uma sequência de cenas que narravam e explicavam o tema escolhido. As duplas, separadamente, tiveram a chance de compartilhar cada um dos trabalhos feitos (Figura 2). Esse momento de atividade em duplas para a produção do roteiro foi subdivido temporalmente em: 2 horas para a montagem do roteiro e mais 2 horas para o compartilhamento dos trabalhos, já quem em média, cada dupla utilizou cerca de 10 minutos para as apresentações. Ao final de cada apresentação, as duplas foram orientadas a fotografarem os seus trabaIhos e postarem na página da disciplina de estágio.

Figura 2: Duplas de alunos realizando as atividades de roteirização, gênero textual abordado presencialmente.

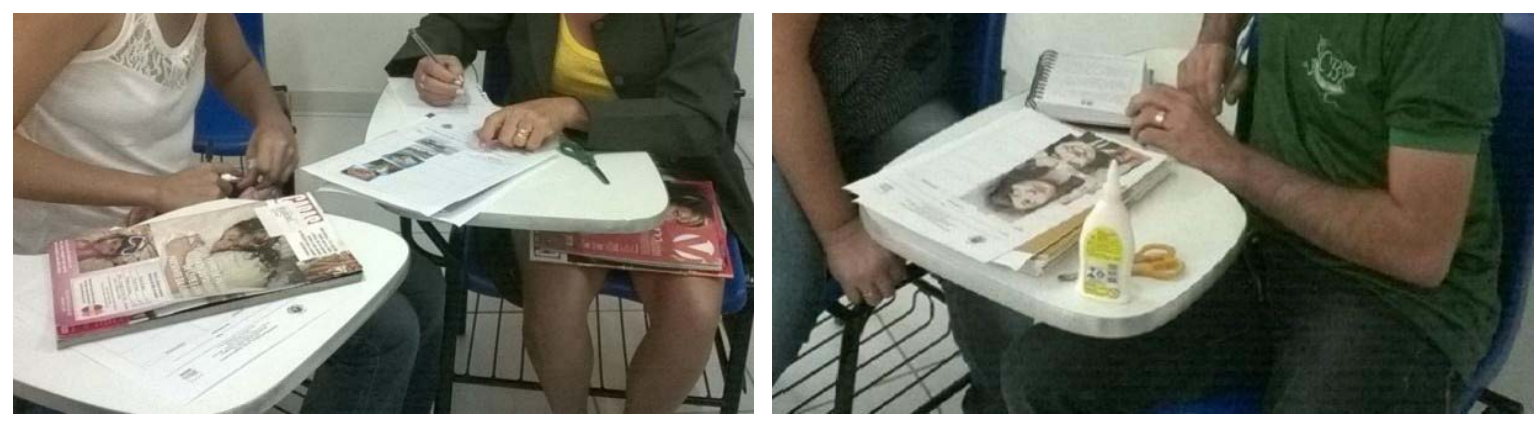

Fonte: autor.

3. Orientações das atividades na página virtual da disciplina de estágio: a terceira estratégia utilizada na busca da melhoria na qualidade dos relatos produzidos pelos alunos envolvidos nas investigações se deu no ambiente virtual, na plataforma Moodle/Mandacaru, especialmente na página da disciplina de estágio. Ao acessarem a página da disciplina, os alunos selecionavam o ícone "Orientações Didáticas" (Figura 3), tendo acesso às orientações referentes a cada uma das postagens no Diário Reflexivo.

Figura 3: Página da disciplina de Estágio Supervisionado do Curso de Licenciatura em Ciências Biológicas da EaD/Sedis/YYYY, na plataforma Moodle/Mandacaru, que dá acesso às orientações para as atividades de postagens nos Diários Reflexivos.

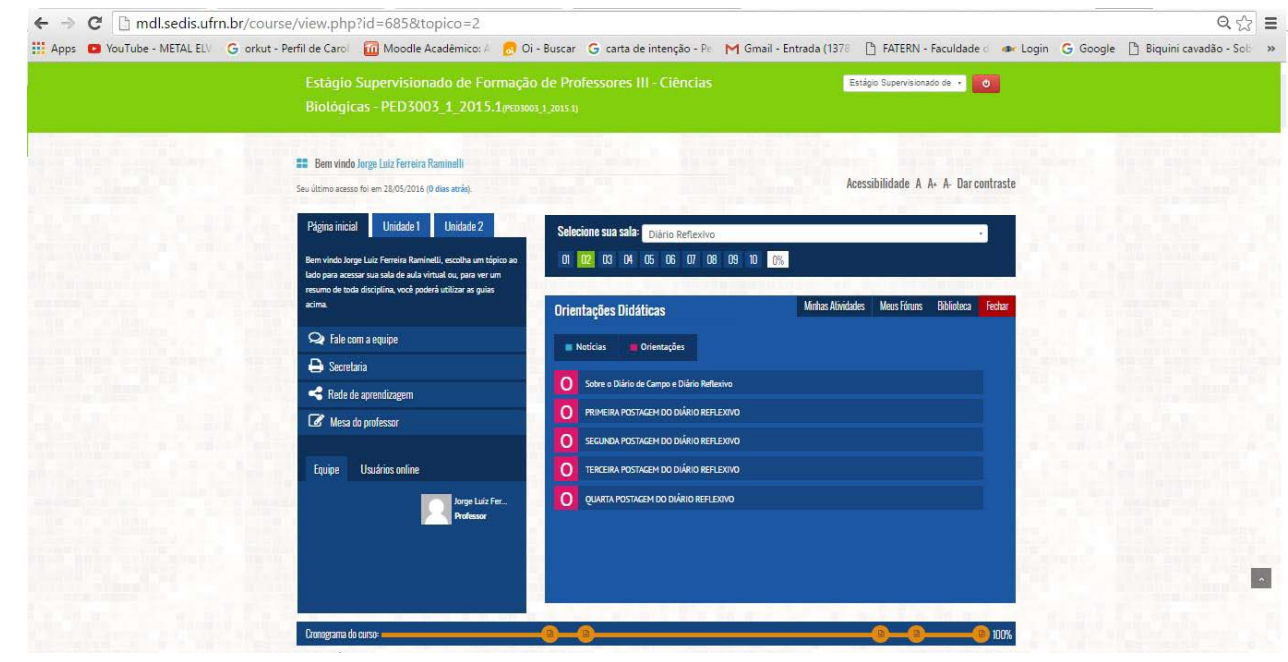

Fonte: https://mdl.sedis.ufrn.br/couse/view.php?id=685\&topico=2. 


\section{Resultados e Discussão}

Vale ressaltar que, anteriormente, as orientações para as narrativas da atividade Diário Reflexivo eram mais abertas, permitindo que o aluno discorresse de temas que não estavam sendo contemplados nas orientações iniciais e, por isso, os textos costumavam ser postados ou com uma simples sinalização de concordância ou discordância da postagem de um colega, ou ainda, com postagens demasiadamente longas, que na grande maioria era recorte de textos pesquisados e que, em grande parte deles, não havia os devidos créditos autorais, caracterizando assim, uma situação de plágio.

Por isso, a importância de deixar claras as orientações a respeito do que seria o Diário de Campo e Diário reflexivo (anexo), norteando melhor as ações dos alunos na plataforma, e nesse ponto, as visitas presenciais aos polos, em que se levantou esses problemas para o grupo, parece ter surtido efeito positivo para a maioria dos alunos, já que grande parte dos textos passou a chegar com referenciais teóricos.

Outro ajuste realizado, uma ação que fez parte do pacote de estratégias interventivas, baseou-se no problema detectado referente às postagens que passaram a ser quinzenais. Antes, essas postagens eram livres e esse fato acarretava em um enorme número de textos postados por um único aluno, havendo semestre em que cada um deles chegava a postar até 10 Diários Reflexivos. Esse excesso na quantidade de postagens parece ter levado a maioria dos alunos a encaminhar seus textos apenas com o intuito de cumprir uma tarefa e, com isso, receber uma pontuação. Para agravar a situação, o trabalho de intervenção realizado pelos professores orientadores e tutores a distância, que exercem um papel essencial na revisão das produções textuais dos alunos e que deveriam devolver esses textos para cada estagiário com sinalizações, orientações e direcionamentos, dado um feedback positivo em tempo hábil, estava ficando bastante prejudicado com o excesso de material a ser revisado.

Vale salientar que esses ajustes ajudaram a melhorar a criticidade à qualidade dos textos, pois os $e$ -alunos passaram, cada vez mais, a valorizar esse quesito.

Nessa direção, ainda como estratégia interventiva para melhorar a qualidade dos textos dos e-alunos e visando sanar este problema, as orientações para as postagens das narrativas passaram a ser mais diretivas, com prazos para cada uma delas, cuidadosamente melhor orientadas no ambiente virtual da disciplina e os temas para cada postagem passaram ser conduzidos de tal forma, no sentido de que fossem descritas as próprias atividades de estágio, ou seja, passou-se a discutir nos diários, não apenas as práticas pedagógicas dos alunos, vivenciadas na escola em um passado recente, mas também, em como esse espaço passou a ser utilizado para discutir e planejar as tarefas futuras do estagiário.

Reforçando ainda a justificativa da utilização das três estratégias interventivas nesta pesquisa, “Exposição dos problemas nos polos; Atividade interventiva nos polos e Orientações das atividades na página virtual", visando essencialmente com isso, que os alunos alcançassem uma aprendizagem realmente significativa na sua formação, Mohamed Ally mostra que estas estratégias deverão conter direcionamentos que visem, acima de tudo:

\footnotetext{
Atenção: colocar uma atividade inicial para desenvolver o processo ensino-aprendizagem; Relevância: esclarecer a importância da lição, mostrar que essa pode ser benéfica para usar em situações da vida real, visa contextualizar e ser mais significativa de maneira a manter o interesse; Confiança: assegurar ao aprendiz que ele obterá êxito nas atividades através da organização do material do simples para o complexo, do conhecido para o desconhecido, informar o que se espera da lição, manter o acompanhamento e o estímulo; Satisfação: fornecer feedback do desempenho, estimular a aplicação do conhecimento na vida real. (ALLY, 2004, p.421). grifo meu.
} 
Outro ponto importante que favoreceu o papel do professor orientador e do tutor a distância foi a redução do número de postagens nos diários, que passaram a ser quatro por semestre, como atividade do ambiente virtual no Moodle. Com isso, reduzindo a quantidade de postagens na atividade, ficou evidente a busca pela qualidade destas narrativas, pois houve mais tempo para um trabalho mais adequado de revisão, que valorizasse a criticidade da escrita por parte do e-aluno. Nesse caso em particular, passaram a chegar à coordenação de estágio, feedbacks positivos enviados pelos e-alunos de estágio ao avaliarem a participação dos e-professores na sua formação.

\section{Considerações Finais}

As três estratégias interventivas propostas pelo professor orientador formador da disciplina de estágio mostraram-se, de certa forma, eficazes para aquilo que se desejou buscar desde o início, a valorização da qualidade do registro narrativo pelos e-alunos de estágio supervisionado da EaD da Universidade Federal do Rio Grande do Norte.

A primeira estratégia, a exposição dos problemas para os alunos e tutores por meio de palestras, bate-papos informais e discussões éticas a respeito da inserção à cibercultura, renderam resultados surpreendentes, evidenciado mudanças para melhor nos relatos produzidos para as tarefas solicitadas. A criticidade do discurso, antes depreciado pelos alunos, passou a aparecer mais frequentemente nas narrativas das ações pedagógicas dos estagiários. Quanto à incorporação da cultura virtual nas práticas diárias do estágio em biologia da EaD, serão necessárias as realizações de novas intervenções, tornando esta uma necessidade básica para estratégias interventivas futuras.

A segunda estratégia interventiva, a produção das atividades de roteirização com os alunos nos polos, ajudou na conscientização da necessidade real de exercitar a construção textual diante da organização das ideias em que se queira transmitir no texto postado como tarefa do Diário reflexivo.

Com a proposta de melhoria na qualidade da atividade Diário Reflexivo, consolidada pelas intervenções dos professores formadores, ficou evidente que as reflexões passaram a fazer parte do cotidiano do e-aluno, refletindo claramente na melhoria dos textos postados nessa atividade.

Por último, a terceira estratégia utilizada valorizou a melhoria da qualidade informativa diante das orientações para a atividade Diário Reflexivo na página da disciplina no ambiente virtual no Moodle/Mandacaru. Os textos postados pelos e-alunos, após essas orientações que permitiram nortear a escrita da narrativa das ações pedagógicas desses estagiários durante as visitas às escolas, passaram a ser mais objetivos e coesos, convergindo numa temática integralmente solicitada para as discussões. Assim, tendo em vista que as narrativas produzidas pelos e-alunos, na tarefa Diário Reflexivo, apresentaram profundas melhoras na sua estrutura, sejam elas organizativas de ideias, sejam na formalização da língua, podemos perceber que o papel interventivo do professor colaborador foi estruturante nesse processo. Esse fato é reforçado pelas ideias de Casado Alves (2015. p. 2), que acredita na imagem formativa do eu em formação sendo consolidada pelo olhar cuidadoso do eu formador, promovendo, nesse caso, uma aprendizagem que se articula (JOSSO, 2004, p.39), com os saberes, os sentidos e com a capacidade colaborativa de cada um.

Percebeu-se também, diante das tentativas de repensar a sua prática dentro do processo de formação docente, que os e-professores orientadores formadores se sentiram inseridos nesse papel, tanto no espaço virtual, quanto no tempo necessário para isso, estando conscientes da sua complementaridade na formação profissional do eu pedagógico desses futuros educadores e educadoras.

Por fim, ao analisarmos a probabilidade de conexão entre as estratégias interventivas realizadas pelos professores formadores - Exposição dos problemas nos polos; Atividade interventiva nos polos e Orientações das atividades na página virtual da disciplina de estágio, que permitiram, por sua vez, a todos os envolvidos, a possibilidade para o diálogo, ser crítico ao se sentir inserido na resolução dos problemas, 
além de se sentirem parte de um coletivo, podemos perceber que houve vinculação entre esses atos pedagógicos propostos com as premissas que regem os ODS 4 - Educação de Qualidade, e 10 - Diminuição das Desigualdades, consequentemente, às metas traçadas pela UFRN na busca pela sustentabilidade, tendo em vista que essas estratégias buscaram, a todo momento, melhorar a qualidade do ensino, ao mesmo tempo em que visava à inclusão de todos, sem exceção.

AGRADECIMENTOS: À Coordenação de Aperfeiçoamento de Pessoal de Nível Superior - Brasil (CAPES) - Código de Financiamento 001, pelo apoio dado à realização do presente artigo.

\section{Referências}

ABED - Associação Brasileira de Educação a Distância. Censo EAD.BR: relatório analítico da aprendizagem a distância no Brasil 2018. Curitiba: Inter Saberes, 2019. Disponível em: http://abed.org.br/ arquivos/CENSO DIGITAL EAD 2018 PORTUGUES.pdf. Acesso em: 13 de jan. 2021.

ALLY, M. Foundations of Education Theory for online learning. 2004. In. TERRY, A. T. e ELIOUMI, F. Theory and Practice of Online Learning. Athabasca: cde. athabascau.ca/online_book, 2004, 421p.

ARRUDA, E. P.; ARRUDA, D. E. P. Educação a Distância no Brasil: Polítivas Públicas e Democratização do Acesso ao Ensino Superior. Educ. rev. vol.31 no.3 Belo Horizonte July/Sept. 2015. Disponível em: https://www.scielo.br/scielo.php?script=sci arttext\&pid=S0102-46982015000300321 . Acessado em 18 de mar. 2021.

BARBOSA, T. M. N.; NORONHA, C. A. Estágio Supervisionado Interdisciplinar. -2. ed.- Natal: EDUFRN. 2013, p. 18.

CASADO ALVES, M. P. Da Literatura, da Imagem e do Ensino: relações dialógicas. In: Linguagens e práticas escolares: leitura, literatura e escrita. Natal: EDUFRN, 2015. p. 123-145.

CIRINO, N. N. (2012) CINEMA INTERATIVO: Problematizações de linguagem e roteirização. Dissertação de Mestrado - Universidade Federal de Pernambuco, CAC. Comunicação. Recife 2012.

COMPARATO, D. Da criação ao roteiro. 5. ed. Rio de Janeiro: Rocco, 2007.

DOSE, E. M. C. A importância do feedback na educação a distância. Revista online de Política e Gestão Educacional, Araraquara, v.21, n.3, p. 1565-1571, set./dez. 2017. ISSN: 1519-9029. Disponível em: file:///C:/Users/Jorge\&Helena/Downloads/andersoncruz-13-10973-carla-ubm-ri.pdf. Acessado em: 14 de fev. 2021.

FRANCO, L. R. H.; BRAGA, D. B. Comunicação virtual. Livro Digital. Curso de Design Instrucional para EaD Virtual. Itajubá: UNIFEI, 2007.

FRANCO, R. K. et al. Aprendizagem na Educação a Distância: Caminhos do Brasil. 2006.

FREIRE, P. Pedagogia do Oprimido. $24^{a}$ ed. Rio de Janeiro: Paz e Terra, 1987, p. 38.

FREIRE, P. Pedagogia da Práxis. São Paulo: Cortez, IPF, 1995.

GATTI, B. A Formação de professores no Brasil: características e problemas. Educ. Soc., Campinas, v. 31, n. 113, p. 1355-1379, out.-dez. 2010. Disponível em: http://www.scielo.br/pdf/es/v31n113/16.pdf. Acesso em: 15 de jul. 2019.

GIL, A. C. Métodos e técnicas de pesquisa social. 6. ed. - São Paulo: Atlas, 2008.

HUCKLE, J. Realizing Sustainability in Changing times. In: STERLING, Stephen; HUCKLE, John. Education for Sustainability. USA, Earthscan. 2014. 278 p. 
JOSSO, MC. Experiências de vida e formação. São Paulo: Cortez, 2004.

LUZ, M. R. M. P. et al. Characterization of the Reasons Why Brazilian Science Teachers Drop Out of Online Professional. Development Courses International Review of Research in Open and Distance Learning.v.19, n5. 2018. Disponível em: file:///C:/Users/Jorge\&Helena/Downloads/3642-28884-1PB-1\%20(1).pdf. Acessado em: 14 de fev. de 2021.

MACHADO, J. B.; CARVALHO, M. J. S. Teoria e prática: as experiências formadoras da docência. CINTED-UFRGS. vol. 11, nº. 2, novembro, 2013.

MEC/ Universidade Aberta do Brasil. Rio Grande do Norte: mapa de demanda por educação profissional.2020. Disponível em: http://portal.mec.gov.br/novoscaminhos/?pagina=mapa-estrategias. Acessado em: 19 de fev. de 2021.

MEC. Educação Superior a Distância. 2017. Disponível em: http://www.planalto.gov.br/ccivil_03/ Ato2015-2018/2017/Decreto/D9057.htm\#art24. Acessado em: 18 de mar. de 2021.

MEC. Subsecretaria de Planejamento e Orçamento (SPO). 2018. Disponível em: http://portal.mec.gov. br/spo-subsecretaria-de-planejamento-e-orcamento. Acessado em: 10 de jan. de 2021.

MENESES, U. T. B. Fontes visuais, cultura visual, História visual. Balanço provisório, propostas cautelares. Revista Brasileira de História. São Paulo, v. 23, n 45, pp. 11-36 - 2003.Disponível em: https://www. scielo.br/pdf/rbh/v23n45/16519.pdf. Acesso em: 6 maio 2020

MESSA, W. C. Utilização de Ambientes Virtuais de Aprendizagem - AVAS: A Busca por uma Aprendizagem Significativa. Revista Brasileira de Aprendizagem Aberta e a Distância - ABED. vol. 9. 2010.

MORAES, M. C. O paradigma educacional emergente. 5. ed. Campinas: Papirus, 2000. 239 p.

ONU. Agenda 2030 para o Desenvolvimento Sustentável. Disponível em: https://nacoesunidas.org/ pos2016/agenda2030/., p.7.Acesso em: 6 mar. 2020

ONU. Agenda 2030 para o Desenvolvimento Sustentável. Disponível em: https://nacoesunidas.org/ pos2016/agenda2030/., p.1. Acesso em: 28 nov. 2020

PORTAL SEDIS. Secretaria de Educação a Distância da Universidade Federal do Rio Grande do Norte. Disponível em: http://www.sedis.ufrn.br/index.php/2011-07-07-08-11-37/conheca. Acesso em: 04 de jun. 2019.a.

PORTAL SEDIS. Secretaria de Educação a Distância da Universidade Federal do Rio Grande do Norte. Disponível em: http://www.sedis.ufrn.br/index.php/2011-07-07-10-32-54/sobre-o-moodle. Acesso em: 04 de jun. 2019.b.

PORTAL SEDIS. Secretaria de Educação a Distância da Universidade Federal do Rio Grande do Norte-Moodle Mandacaru. 2014. Disponível em://177.20.146.36/index.php/zoo/item/novo-moodle-academico Acesso em: 13 de jan. 2021.

PROPLAN/ SIGAA/ SIGRH. Relatório PROGESP 2018. Disponível em: https://ufrn.br/resources/documentos/ufrnemnumeros/UFRN-em-Numeros-2014-2018.pdf. Acesso em: 29 abr. 2020.

SOUZA, F. M. de. Um documento chamado roteiro. Disponível em: http://www.roteirodecinema.com.br/ manuais/documentochamadoroteiro.htm. 2016. Acesso em: 31 maio 2019.

UFRN. Sistema Integrado de Gestão de Atividades Acadêmicas (SIGAA). 2020. Disponível em: https:// sigaa.ufrn.br/sigaa/portais/discente/discente.jsf. Acesso em: 12 maio de 2020.

YIN, R. K. Estudo de caso: planejamento e métodos. 4. ed. Porto Alegre: Bookman, 2010. 